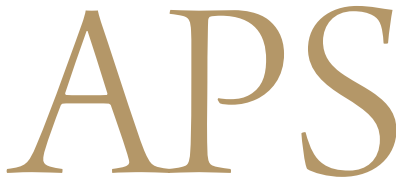

Archives of Plastic Surgery

\title{
Nasal Anthropometry on Facial Computed Tomography Scans for Rhinoplasty in Koreans
}

\author{
Kyung Min Moon, Geon Cho, Ha Min Sung, Min Su Jung, Kyoung Seok Tak, Sung-Won Jung, \\ Hoon-Bum Lee, In Suck Suh \\ Department of Plastic and Reconstructive Surgery, Kangnam Sacred Heart Hospital, Hallym University College of Medicine, Seoul, Korea
}

Background Cephalometric analysis is essential for planning treatment in maxillofacial and aesthetic facial surgery. Although photometric analysis of the Korean nose has been attempted in the past, anthropometry of the deeper nasal structures in the same population based on computerized tomography (CT) has not been published. We therefore measured three anthropometric parameters of the nose on $\mathrm{CT}$ scans in our clinical series of patients.

Methods We conducted the current retrospective study of a total of 100 patients $(n=100)$ who underwent a CT-guided radiological measurement at our institution during a period ranging from January of 2008 to August of 2010. In these patients, we took three anthropometric measurements: the nasofrontal angle, the pyramidal angle, and the linear distance between the nasion and the tip of the nasal bone.

Results The mean nasofrontal angle was $131.14^{\circ}$ in the male patients and $140.70^{\circ}$ in the female patients. The mean linear distance between the nasion and the tip of the nasal bone was $21.28 \mathrm{~mm}$ and $18.02 \mathrm{~mm}$, respectively. The mean nasal pyramidal angle was $112.89^{\circ}$ and $103.25^{\circ}$ at the level of the nasal root, $117.49^{\circ}$ and $115.60^{\circ}$ at the middle level of the nasal bone, and $127.99^{\circ}$ and $125.04^{\circ}$ at the level of the tip of the nasal bone, respectively.

Conclusions In conclusion, our data will be helpful in the preparation of silicone implants for augmentation and/or corrective rhinoplasty in ethnic Korean people.

Keywords Anthropometry / Nose / Rhinoplasty / Korea
Correspondence: In Suck Suh Department of Plastic and Reconstructive Surgery, Kangnam Sacred Heart Hospital, Hallym University College of Medicine, 1 Singil-ro, Yeongdeungpo-gu, Seoul 150-950, Korea

Tel: +82-2-829-5182

Fax: +82-2-847-5183

E-mail: sismdps@chollian.net

Received: 27 Feb 2013 - Revised: 1 Jul 2013 • Accepted: 10 Jul 2013

pISSN: 2234-6163 • elSSN: 2234-6171 • http://dx.doi.org/10.5999/aps.2013.40.5.610 • Arch Plast Surg 2013;40:610-615

This article was presented at the 68th Congress of the Korean Society of Plastic and Reconstructive Surgeons on Nov 4-7, 2010 in Seoul, Korea.

No potential conflict of interest relevant to this article was reported.

\section{INTRODUCTION}

The nose is an organ that plays a key role in performing certain anatomical and physiologic functions. In addition, it is the most prominent organ on the face, located in its center [1]. Furthermore, it forms a harmony with other facial structures. Thus, it plays an important role in determining an individual's external appearance [2]. Ethnic Koreans are commonly found to have a flat, depressed nose that is generally characterized by 1 ) a low nasal dorsum, 2) a bulbous, thick nasal tip, 3) a small, thin, weak alar cartilage, 4) a short columella, and 5) lesser prominence of the nasal tip [1]. To date, while attempts have been made to perform a photometric analysis of the typical Korean nose, no analysis of the nasal bone other than that of the soft tissue has been carried out. Craniofacial anthropometry has been actively used in the field of anthropology and medicine. Thus, it has greatly contributed to not only conducting comparative studies between different ethnic populations, but also establishing di- 
agnostic and treatment guidelines in the field of plastic surgery and other clinical specialties. Early craniofacial anthropometric studies were conducted mainly using a biometric or a photometric analysis. However, the inability to directly analyze the nasal bone, as opposed to the soft tissue, posed limitations. As a more accurate modality than a simple X-ray, a facial computed tomography (CT) can now be used to analyze the nasal bone from various angles.

Given the above background, we measured three anthropometric parameters (the nasofrontal angle, the nasal pyramidal angle, and the linear distance between the nasion and the tip of the nasal bone) in our clinical series of 100 patients. In addition, we compared our measurements of the three parameters and photometric results to the findings in the literature. Furthermore, we also compared the cephalometric measurements of the nasofrontal angle of our subjects with those of Caucasians.

\section{METHODS}

\section{Study patients}

We conducted the current retrospective study for a total of 100 patients $(n=100)$ who underwent a CT-guided radiological measurement for the diagnosis and treatment of facial trauma at our medical institution during a period ranging from January of 2008 to August of 2010. In the current study, the patients underwent CT scans at their own expense. In these patients, we measured three anthropometric parameters associated with augmentation rhinoplasty including the nasofrontal angle, the pyramidal angle, and the linear distance between the nasion and the tip of the nasal bone. Inclusion criteria were a lack of the following: a notable deformity in the nasal bone, bone defects, or facial disorders. Exclusion criteria were nasal bone fractures or a deviated nose. The current study was approved by the Institutional Review Board of our medical institution.

\section{Fig. 1. The facial mid-sagittal computed tomography scan}

(A) Mid-sagittal view. A, most protuberant point of glabella; B, nasion; $\mathrm{C}$, tip of nasal bone. (B) Scout image.
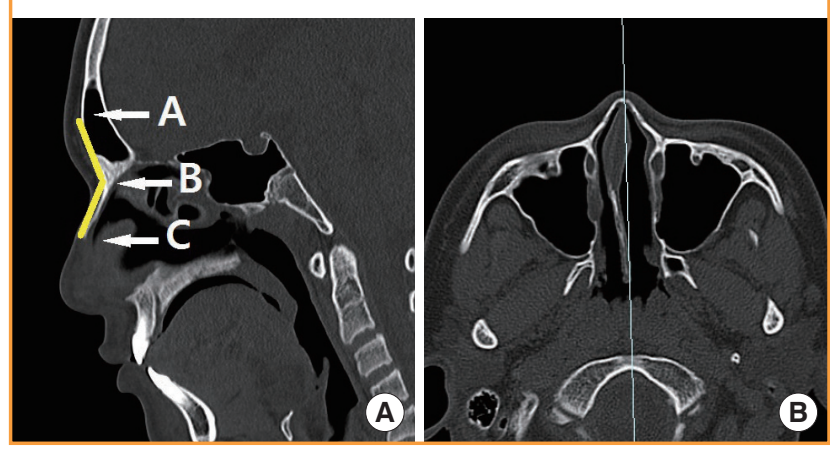

\section{Measurement}

We used a CT scanner, 64-slide MDCT Somatom Sensation 64 (Siemens, Munich, Germany), together with STAR PACS (Infiniti, Seoul, Korea). The CT settings were $120 \mathrm{kVp}$, a rotation time of 1 second, a table feed of $0.5 \mathrm{~mm} / \mathrm{sec}$, and a slice thickness of $2 \mathrm{~mm}$.

We measured the following three anthropometric parameters: 1) Nasofrontal angle: the angle formed between the nasal bone and the frontal bone. 2) Pyramidal angle: the angle formed between the bilateral nasal bones. 3) Linear distance between the nasion and the tip of the nasal bone.

On mid-sagittal CT scans, we set point $\mathrm{A}$ at the most protuberant point of the glabella. In addition, we also set point $\mathrm{B}$ at the nasion, which is the center of the nasofrontal suture, and $\mathrm{C}$ at the nasal bone tip, which is the most protuberant and lowest point of the nasal bone. Then, we measured not only the angle formed between $\mathrm{A}, \mathrm{B}$, and $\mathrm{C}$ but also the linear distance between $B$ and C (Fig. 1).

On axial CT scans, we measured the pyramidal angle at the level of the nasal root, the level of the tip of the nasal bone, and the middle of the two levels. We set point $\mathrm{D}$ at three levels: the level of the nasal root (the top of the nose, forming an indentation at the suture where the nasal bones meet the frontal bone), the middle level (the actual middle point between the nasal root and the tip of the nasal bone), and the level of the tip of the nasal bone (the most protuberant and lowest point of the nasal bone). In addition, we set points $\mathrm{E}$ and $\mathrm{F}$ at the tangent points derived from $\mathrm{D}$ to the right and left nasal bones, respectively. Then, we measured the angle formed between D, E, and F (Fig. 2).

\section{RESULTS}

Our clinical series of patients $(n=100)$ consisted of 50 men and 50 women with a male-to-female ratio of $1: 1$. With regard to the

\section{Fig. 2. The facial axial computed tomography scan}

(A) Axial view. D, the middle of the nasal root and the tip of the nasal

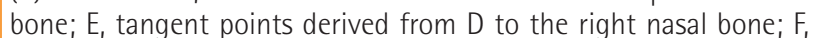
tangent points derived from $D$ to the left nasal bone. (B) Scout image.
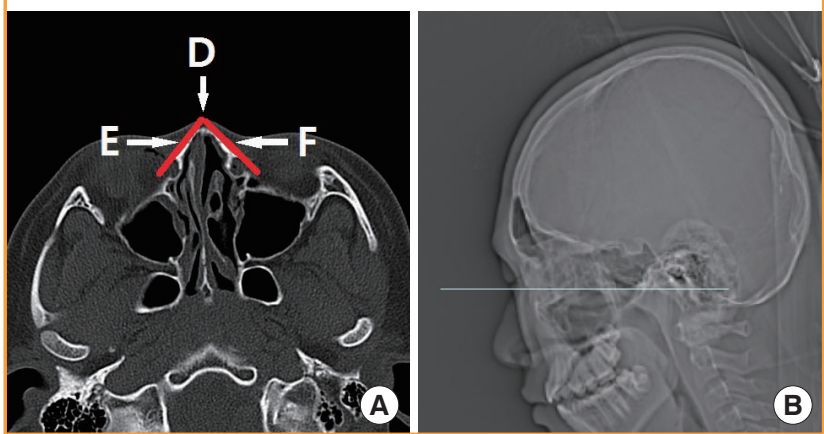
age distribution, there were 25 patients $(n=25)$ in their 20 s, 15 patients $(n=15)$ in their 30 s, and 10 patients $(n=10)$ aged 40 years or older. The patient data is summarized in Table 1.

\section{Nasofrontal angle and the linear distance between the landmarks}

Overall, the mean nasofrontal angle was $131.14^{\circ}$ (range, $112.93^{\circ}$ $\left.146.62^{\circ}\right)$ in the male patients $(\mathrm{n}=50)$ and $140.70^{\circ}$ (range, $113.88^{\circ}$ $\left.162.80^{\circ}\right)$ in the female patients $(\mathrm{n}=50)$.

More specifically, the mean nasofrontal angles were $131.65^{\circ}$ in the male patients and $142.95^{\circ}$ in the female patients in their 20s; $131.92^{\circ}$ in the male patients and $139.32^{\circ}$ in the female patients in their 30s; and $128.11^{\circ}$ in the male patients and $135.79^{\circ}$ in the female patients in their 40s (Table 2).

Measurements of the nasofrontal angle showed that $40 \%$ of the male patients and $12 \%$ of the female patients had a nasofrontal angle of $<130^{\circ}$ (lesser obtuse angle); $58 \%$ of the male patients and $52 \%$ of the female patients had a nasofrontal angle of $130^{\circ}$ to $145^{\circ}$ (obtuse angle); and $2 \%$ of the male patients and $36 \%$

Table 1. Baseline characteristics of patients
\begin{tabular}{|lcc|}
\hline \multicolumn{3}{|l|}{} \\
\hline Age group (yr) & Male & Female \\
\hline $20-29$ & 25 & 25 \\
$30-39$ & 15 & 15 \\
$40 \leq$ & 10 & 10 \\
\hline
\end{tabular}

\section{Table 2. Nasofrontal angle}

\begin{tabular}{|lcc|}
\hline \multirow{2}{*}{ Age group $(y r)$} & \multicolumn{2}{c|}{ Mean of angle $\left(^{\circ}\right)$} \\
\cline { 2 - 3 } & Male $(n=50)$ & Female $(n=50)$ \\
\hline $20-29$ & $131.65(n=25)$ & $142.95(n=25)$ \\
$30-39$ & $131.92(n=15)$ & $139.32(n=15)$ \\
$40-49$ & $128.11(n=7)$ & $135.79(n=7)$ \\
$50-59$ & $130.14(n=3)$ & $140.30(n=3)$ \\
Range of angle & $112.93-146.62$ & $113.88-162.80$ \\
Mean of angle & 131.14 & 140.70 \\
\hline \multicolumn{3}{|c}{} \\
\hline
\end{tabular}

of the female patients had a nasofrontal angle of $>145^{\circ}$ (more obtuse angle) (Fig. 3).

The linear distance between $\mathrm{B}$ and $\mathrm{C}$ (B, the nasion; and C, the tip of the nasal bone) was $21.28 \mathrm{~mm}$ in the male patients $(\mathrm{n}=50)$ and $18.02 \mathrm{~mm}$ in the female patients $(\mathrm{n}=50)$ (Table 3$)$.

\section{Pyramidal angle of the nasal bone}

At the level of the nasal root, the mean nasal pyramidal angle was $112.89^{\circ}$ (range, $70.93^{\circ}-145.52^{\circ}$ ) in the male patients and $103.25^{\circ}$ (range, $75.59^{\circ}-131.12^{\circ}$ ) in the female patients. Specifically, the mean nasal pyramidal angles were $109.03^{\circ}$ in the male patients and $98.98^{\circ}$ in the female patients in their 20 s; $106.05^{\circ}$ in the male patients and $107.20^{\circ}$ in the female patients in their 30s; and $89.03^{\circ}$ in the male patients and $112.00^{\circ}$ in the female patients in their 40s (Table 4). At the middle level of the nasal bone, it was $117.49^{\circ}$ (range, $99.96^{\circ}-139.93^{\circ}$ ) in the male patients and $115.60^{\circ}$ (range, $97.94^{\circ}-135.15^{\circ}$ ) in the female patients. By

\section{Table 3. Distance between the nasion and the glabella (B-C)}

\begin{tabular}{|lcc|}
\hline \multirow{2}{*}{ Age group $(y r)$} & \multicolumn{2}{c|}{ Mean of distance $(B-C)$} \\
\cline { 2 - 3 } & Male $(n=50)$ & Female $(n=50)$ \\
\hline $20-29$ & $21.57(n=25)$ & $17.84(n=25)$ \\
$30-39$ & $21.77(n=15)$ & $18.92(n=15)$ \\
$40-49$ & $20.39(n=7)$ & $17.47(n=7)$ \\
$50-59$ & $18.42(n=3)$ & $16.31(n=3)$ \\
Mean of distance & 21.28 & 18.02 \\
\hline
\end{tabular}

Table 4. Nasal pyramidal angle at the level of the nasal root

\begin{tabular}{|lcc|}
\hline \multirow{2}{*}{ Age group $(\mathrm{yr})$} & \multicolumn{2}{c|}{ Mean of angle $\left(^{\circ}\right)$} \\
\cline { 2 - 3 } & Male $(n=50)$ & Female $(n=50)$ \\
\hline $20-29$ & $109.03(n=25)$ & $98.98(n=25)$ \\
$30-39$ & $106.05(n=15)$ & $107.20(n=15)$ \\
$40-49$ & $89.03(n=7)$ & $112.00(n=7)$ \\
$50-59$ & $110.17(n=3)$ & $98.02(n=3)$ \\
Range of angle & $70.93-145.52$ & $75.59-131.12$ \\
Mean of angle & 112.89 & 103.25 \\
\hline
\end{tabular}

\section{Fig. 3. Classification of the nasofrontal angle}

(A) Nasofrontal angle, $<130^{\circ}$. (B) Nasofrontal angle, $130^{\circ}-145^{\circ}$. (C) Nasofrontal angle, $>145^{\circ}$.
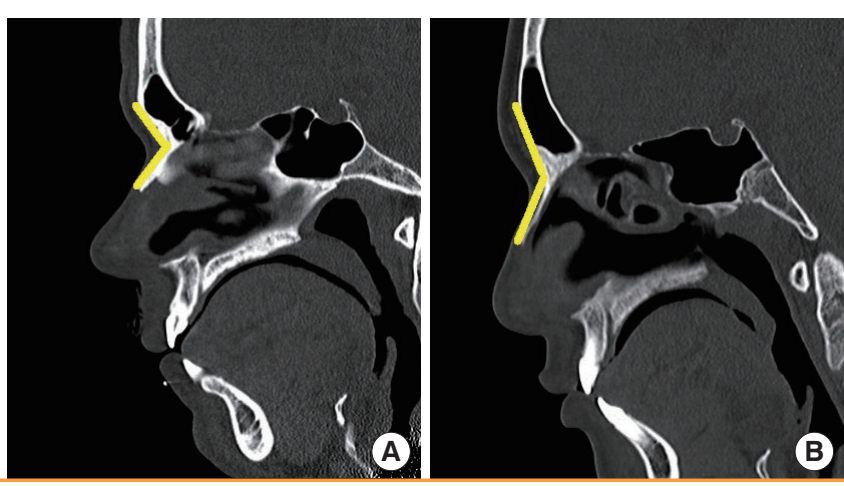


\section{Fig. 4. Classification of the nasofrontal angle}

(A) Nasal pyramidal angle, $<100^{\circ}$.

(B) Nasal pyramidal angle, $100^{\circ}-$ $115^{\circ}$. (C) Nasal pyramidal angle, $>115^{\circ}$.
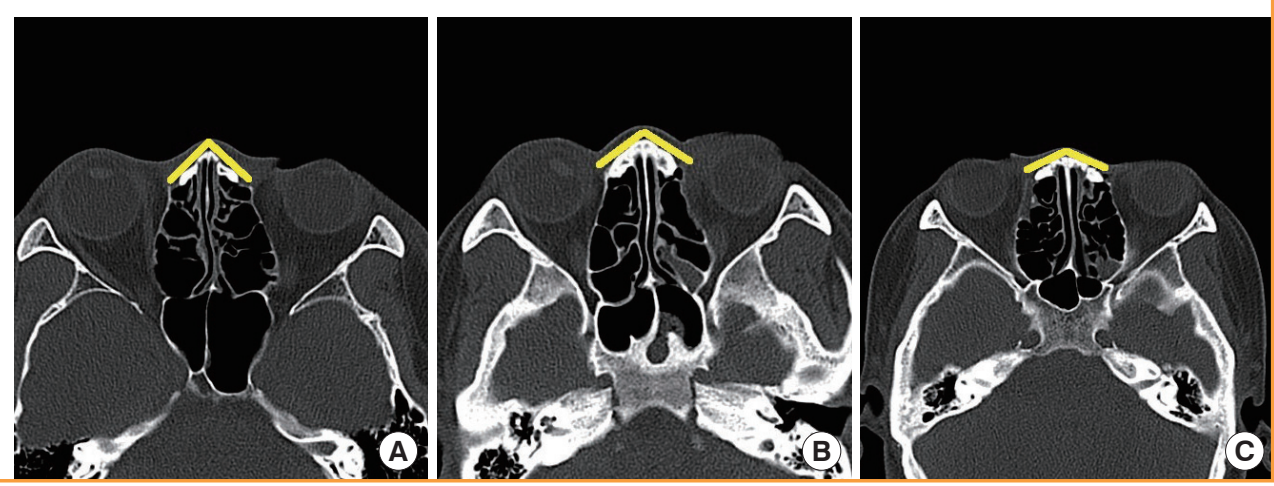

Table 5. Nasal pyramidal angle at the middle level of nasal bone

\begin{tabular}{|lcc|}
\hline \multirow{2}{*}{ Age group $(\mathrm{yr})$} & \multicolumn{2}{c|}{ Mean of angle $\left({ }^{\circ}\right)$} \\
\cline { 2 - 3 } & Male $(\mathrm{n}=\mathbf{5 0})$ & Female $(\mathrm{n}=\mathbf{5 0})$ \\
\hline $20-29$ & $121.17(n=25)$ & $115.61(n=25)$ \\
$30-39$ & $112.67(n=15)$ & $116.58(n=15)$ \\
$40-49$ & $117.06(n=7)$ & $113.26(n=7)$ \\
$50-59$ & $111.88(n=3)$ & $116.08(n=3)$ \\
Range of angle & $99.96-139.93$ & $97.94-135.15$ \\
Mean of angle & 117.49 & 115.60 \\
\hline
\end{tabular}

age, the mean nasal pyramidal angles were $121.17^{\circ}$ in the male patients and $115.61^{\circ}$ in the female patients in their 20s; $112.67^{\circ}$ in the male patients and $116.58^{\circ}$ in the female patients in their 30s; and $117.06^{\circ}$ in the male patients and $113.26^{\circ}$ in the female patients in their 40s (Table 5). At the level of the nasal bone tip, it was $127.99^{\circ}$ (range, $96.97^{\circ}-149.80^{\circ}$ ) in the male patients and $125.04^{\circ}$ (range, $98.22^{\circ}-145.28^{\circ}$ ) in the female patients. By age, the mean nasal pyramidal angles were $132.34^{\circ}$ in the male patients and $124.93^{\circ}$ in the female patients in their 20s; $127.71^{\circ}$ in the male patients and $128.44^{\circ}$ in the female patients in their 30 s; and $126.11^{\circ}$ in the male patients and $120.89^{\circ}$ in the female patients in their 40s (Table 6).

Based on measurements of the nasal pyramidal angle at the level of the nasal root, $24 \%$ of the male patients and $38 \%$ of the female patients had a pyramidal angle of $<100^{\circ}$ (acute-angled pyramid); $38 \%$ of the male and female patients each had a pyramidal angle of $100^{\circ}-115^{\circ}$ (obtuse-angled pyramid); and 38\% of male patients and $24 \%$ of female patients had a pyramidal angle of $>115^{\circ}$ (more obtuse-angled pyramid) (Fig. 4).

\section{DISCUSSION}

In the past, facial CT examinations have not been widely used to preoperatively evaluate the possible occurrence of side effects or complications. At present, however, a CT scan is performed
Table 6. Nasal pyramidal angle at the level of nasal bone tip

\begin{tabular}{|lcc|}
\hline \multirow{2}{*}{ Age group $(\mathrm{yr})$} & \multicolumn{2}{c|}{ Mean of angle $\left(^{\circ}\right)$} \\
\cline { 2 - 3 } & Male $(\mathrm{n}=50)$ & Female $(\mathrm{n}=50)$ \\
\hline $20-29$ & $132.34(n=25)$ & $124.93(n=25)$ \\
$30-39$ & $127.71(n=15)$ & $128.44(n=15)$ \\
$40-49$ & $126.11(n=7)$ & $120.89(n=7)$ \\
$50-59$ & $107.49(n=3)$ & $118.56(n=3)$ \\
Range of angle & $96.97-149.80$ & $98.22-145.28$ \\
Mean of angle & 127.99 & 125.04 \\
\hline
\end{tabular}

preoperatively for accurate evaluation.

In the current study, we examined the anthropometric measurements of the nose in facial CT scans of our clinical series of patients because we speculated that our data would be helpful in preparing for silicone implants for augmentation and/or corrective rhinoplasty in Koreans. To date, facial anthropometric studies have been actively conducted in the fields of anthropology and medicine [3]. This has greatly contributed to establishing diagnostic and treatment guidelines in the field of plastic surgery and other clinical areas as well as to the performance of comparative studies between different ethnic populations [4]. Unlike biometric analysis [5], radiological anthropometry is the measurement of the distance or angle between two points on a projected plane. However, because the 3-dimensional stereoscopic location of the face is determined in a 2-dimensional manner, there might be some discrepancy in the magnitude of the measurements, depending on the sites, between radiological anthropometry and biometric analysis [6]. Nonetheless, radiological anthropometry is more effective in measuring the slope or angle with greater ease and accuracy compared with biometric analysis [7]. It has also been reported that there is almost no significant difference in the magnitude of the measurements between radiological anthropometry and biometric analysis [8]. With the latest technical advancement of facial aesthetic surgery, data from photographic measurements or biometric analysis 
has been used as baseline data in facial contouring or other reconstructive operations [9]. Due to the lack of studies providing normal reference criteria based on radiological measurements of the face in Korean people, making a preoperative plan was difficult. We therefore analyzed the distance, angle, and slope between the nasal bones through a standardized CT-guided radiological measurement of adult Korean men and women.

The nasofrontal angle, pyramidal angle, and linear distance between the nasion and the tip of the nasal bone are key factors that should be considered for augmentation and/or corrective rhinoplasty.

It is important to carve the dorsal surface of silicone implants deeply enough to create a concave shape. This generates a negative pressure so that the silicone implant can have good contact with the nasal bone on its dorsal surface, thus achieving compatibility with the nasal dorsum. This leads to the formation of a homogeneous layer, achieving a stable fixation in the pocket. Moreover, the silicone implant should be carved to the nasofrontal angle, pyramidal angle, and the linear distance between the nasion and the tip of the nasal bone so that it makes good contact with the nasal bone.

The formation of dead space is unavoidable, not only because manual carving cannot be done precisely, but also because of the lack of precise contact between the nasal bone and the silicone implant. This can also lead to the occurrence of complications such as hematoma, infection, or the deviation of the implant.

By carving a silicone implant to the nasofrontal angle, pyramidal angle, and the linear distance between the nasion and the tip of the nasal bone, the compatibility between the silicone implant and the nasal bone will be increased. In addition, the likelihood of postoperative complications will be reduced.

In our series, the mean nasofrontal angle was $131.14^{\circ}$ in the male patients and $140.70^{\circ}$ in the female patients. Similarly, Lee et al. [3] reported that the mean nasofrontal angle based on clinical photography was $136.89^{\circ}$ in 120 normal Korean women who had no facial disorders aged between 18 and 45 years. Kim et al. [10] measured the mean nasofrontal angle through clinical photography in 1,483 normal Korean men and in 1,419 normal Korean women, both of whom were aged between 18 and 80 years and had no past history of facial deformity or craniofacial surgery. They reported a mean nasofrontal angle of $138.2^{\circ}$ in the men and $142.7^{\circ}$ in the women. These reports showed no great difference from our findings. In addition, Leong and White [11] conducted a cephalometric study in 57 Caucasian people. These authors reported that the nasofrontal angle was $129.0^{\circ}$ in the male patients and $135.3^{\circ}$ in the female patients. Based on these results, we can conclude not only that the nasofrontal angle of the female patients is more obtuse than that of the male patients both in Korean and Caucasian people but also that the nasofrontal angle of Koreans is more obtuse than that of Caucasian people. Presumably, this could be a function of ethnic differences.

Based on a review of the literature, no reports were found to provide facial measurements of the nasal pyramidal angle in Koreans. Our results showed that the mean value of the nasal pyramidal angle was $112.89^{\circ}$ in the male patients and $103.25^{\circ}$ in the female patients. It should also be noted that there was variability of the nasal pyramidal angle among individuals. These results might be of use when performing rhinoplasty.

To summarize, our results are as follows: 1) The mean nasofrontal angle was $131.14^{\circ}$ (range, $112.93^{\circ}-146.62^{\circ}$ ) in the male patients $(\mathrm{n}=50)$ and $140.70^{\circ}$ (range, $\left.113.88^{\circ}-162.80^{\circ}\right)$ in the female patients $(n=50) .2)$ The mean linear distance between the nasion and the tip of the nasal bone was $21.28 \mathrm{~mm}$ in the male patients $(\mathrm{n}=50)$ and $18.02 \mathrm{~mm}$ in the female patients $(\mathrm{n}=50)$. 3) The mean nasal pyramidal angle was $112.89^{\circ}$ (range, $70.93^{\circ}$ $145.52^{\circ}$ ) in the male patients and $103.25^{\circ}$ (range, $75.59^{\circ}-131.12^{\circ}$ ) in the female patients at the level of the nasal root; $117.49^{\circ}$ (range, $99.96^{\circ}-139.93^{\circ}$ ) and $115.60^{\circ}$ (range, $97.94^{\circ}-135.15^{\circ}$ ) at the middle level of the nasal bone; and $127.99^{\circ}$ (range, $96.97^{\circ}-149.80^{\circ}$ ) and $125.04^{\circ}$ (range, $98.22^{\circ}-145.28^{\circ}$ ) at the level of the tip of the nasal bone, respectively.

In conclusion, our data will be helpful for enhancing compatibility between silicone implants and the nasal bone and for decreasing the occurrence of postoperative complications in augmentation and/or corrective rhinoplasty in Koreans.

\section{REFERENCES}

1. Kim SM. Aesthetic rhinoplasty for the improvement of the lateral facial profile; image-up rhinoplasty. J Korean Soc Plast Reconstr Surg 2005;32:205-13.

2. Choi JY, Min CG, Myoung H, et al. Nasal augmentation using Gore-Tex. J Korean Assoc Maxillofac Plast Reconstr Surg 2003;25:331-6.

3. Lee DJ, Kim WK, Chung CE, et al. Photogrammetric study on the face of adult Korean female. J Korean Soc Plast Reconstr Surg 1989;16:423-32.

4. D'Ottaviano N, Baroudi R. Surgical and esthetic aspects of the facial profile. Int J Oral Surg 1974;3:243-6.

5. Peck H, Peck S. A concept of facial esthetics. Angle Orthod 1970;40:284-318.

6. Paik DH, Han KH, Won DC, et al. Accuracy of indirect anthropometry on cast model of the nose: comparison with direct anthropometry. J Korean Soc Plast Reconstr Surg 2008; 35:47-54.

7. Farkas LG, Bryson W, Klotz J. Is photogrammetry of the 
face reliable? Plast Reconstr Surg 1980;66:346-55.

8. Sushner NI. A photographic study of the soft-tissue profile of the Negro population. Am J Orthod 1977;72:373-85.

9. Lee YJ, Han KH, Kang JS. Korean standards of craniomaxillofacial skeleton. J Korean Soc Plast Reconstr Surg 1994;21:438-51.
10. Kim SH, Jo DI, Kim CK, et al. Anthropometric analysis of mid-face; senile changes of nasal dimensions. Arch Aesthetic Plast Surg 2012;18:81-8.

11. Leong SC, White PS. A comparison of aesthetic proportions between the Oriental and Caucasian nose. Clin Otolaryngol Allied Sci 2004;29:672-6. 